\title{
Bacterial Culture Dependent Effect on Mobile Phone's Surface
}

\author{
S. Sheik Asraf, V. Priyanga, P. S. Bhuvaneshwaran, M. Devanand
}

\begin{abstract}
Mobile phones from people of different walks of life were examined through culture dependent based approach. Bacteria were isolated from the surface of the mobile phones. Various microbiological and biochemical tests such as Gram staining, citrate utilization test, urease test, TSI test, catalase test, methyl red test and indole test were performed for the isolated bacteria. This study highlights the health risk posed by the microbiota in the mobile phone's surface.
\end{abstract}

Keywords: Culture dependent, Mobile phone, Microbiota

\section{INTRODUCTION}

In a recent study conducted in an Egyptian University, it was found that bacteria belonging to the following Genus were found abundant in the mobile phones of staffs: Gordonia, [1]. There has also a report of bacterial growth observed on mobile and non-mobile phones used by anesthetists in an operation theatre [2].Moreover, higher levels of antibiotic resistant bacterial populations were reported from mobile phones in a hospital [3]. More recently, it was found that mobile phones act as vector for transmission of bacteria [4]. Often, mobile phones used by teaching professionals are vulnerable for bacterial growth [5]. Hospitalized patients' mobile phones act as point of transmission of bacteria from one person to another person [6]. This prompted us to up through microbiological and biochemical methods. We had selected the mobile phones from the following group of individuals such as faculty, student, sweeper, lab technician and mechanic. Biochemical and Microbiological tests like Gram staining, citrate utilization test, urease test, TSI test, catalase test, methyl red test and indole test were performed for the bacterial isolates because they are the preliminary tests to examine the type of the bacteria. This study highlights the potential threat posed by the microbiota in mobile phones to the users.

Revised Manuscript Received on December 15, 2019.

* Correspondence Author

S. Sheik Asraf*, Department of Biotechnology, Kalasalingam Academy of Research and Education, Anand Nagar, Krishnankoil, India. Email: s.sheikasraf@klu.ac.in

V. Priyanga, Department of Biotechnology, Kalasalingam Academy of Research and Education, Anand Nagar, Krishnankoil, India. Email: priyavasudev1996@gmail.com

P. S. Bhuvaneshwaran, Department of Biotechnology, Kalasalingam Academy of Research and Education, Anand Nagar, Krishnankoil, India. Email: bhuvanssb@gmail.com

M. Devanand, Department of Biotechnology, Kalasalingam Academy of Research and Education, Anand Nagar, Krishnankoil, India. Email: devanand.m20@gmail.com Pantoea, Ochrobactrum, Staphylococcus and Bacillus spp examine the microbiota of mobile phones in our university set

\section{MATERIALS, METHODS, RESULT AND DISCUSSION}

A. Isolation of bacteria from mobile phones by culture dependent technique

Isolation of the bacteria from mobile phones by swab plate method was performed (Figure 1).

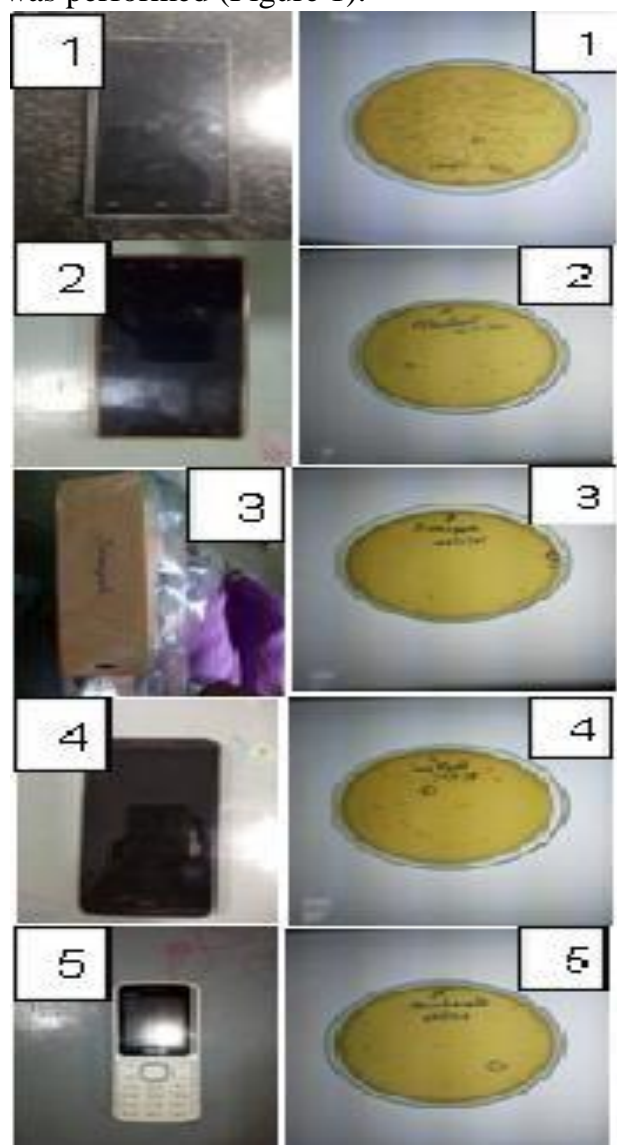

Fig. 1.Swab plate method of isolating the bacteria from mobile phone's surface. Bacterial isolates from 1-faculty,

2-student, 3- sweeper, 4-lab technician, 5-mechanic respectively.

\section{B. Simple staining}

The isolated bacteria was taken on an unsoiled slide and spread using inoculation loop. The bacterial smear was air dried, warmed and heat fixed by passing the slide from side to side of the bunsen flame multiple times. Crystal violet was supplemented dropwise and set aside for 15-60 S. The slide was washed in tap water and permitted to air dehydration and later examined under microscope. Rod profile of bacteria was seen [7].

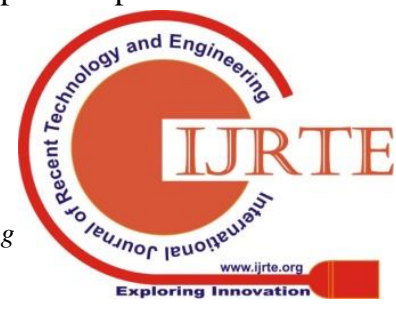




\section{Gram staining}

The isolated bacteria was taken on an unsoiled slide and spread using inoculation loop. The bacterial smear was air dried and heat set. Crystal violet was inundated over the smear and left untouched for 40-60 S and was bathed with tap water. Gram's iodine was supplemented as a mordant for 1 minute and later the slide was washed in tap water. Discoloring agent was added drop by drop till the primary stain stops exhausting from the smear and later rinsed with tap water. Safranin was supplemented as counter stain and the slide was set aside for 1 minute and later bathed with running tap water. The slide was scrutinized under microscope [8]. The bacterial isolates of the mobile phones were found to be Gram positive.

\section{Catalase test}

Glass test tubes were taken and the bacterial isolates of the mobile phones were added with the help of pipette. 2-3 drops of hydrogen peroxide was added to the bacterial culture [9]. Oxygen bubbles evolved indicating positive result for catalase (Figure 2).

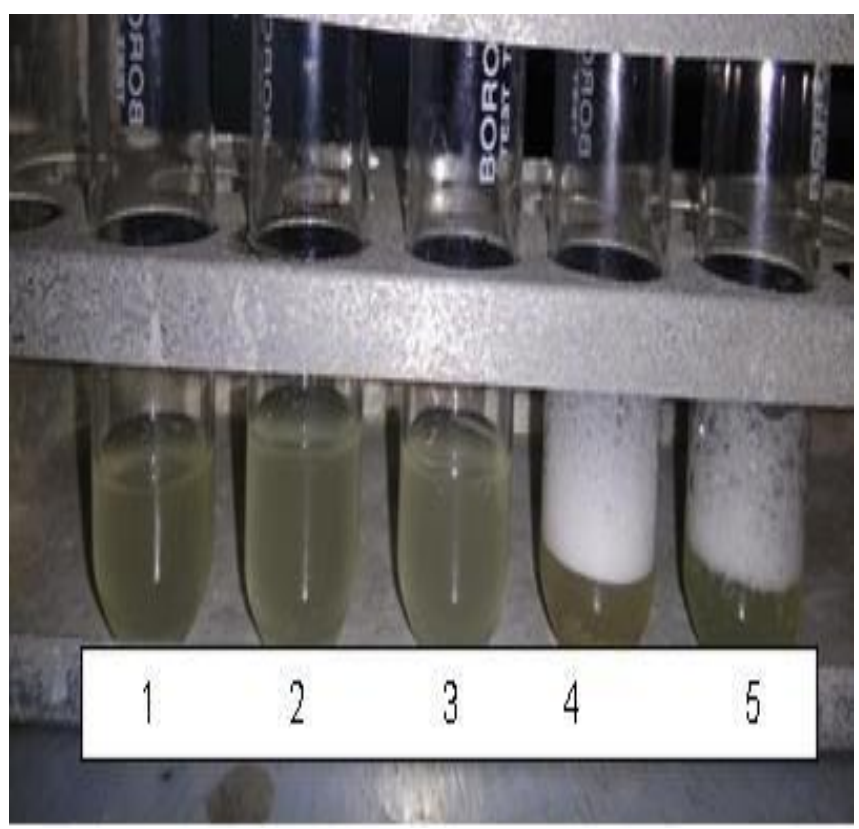

Fig. 2. Catalase test of bacterial isolates.1,2,3,4,5 are the catalase results of bacterial isolates from 1-faculty, 2-student, 3- sweeper, 4-lab technician, 5-mechanic respectively.

\section{E. Indole test}

The peptone broth was readied and later relocated to the test tube. The test tube was autoclaved at $121^{\circ} \mathrm{C}$ at $15 \mathrm{lbs}$ pressure for 15 minutes and later the bacterial isolates of the mobile phones was introduced into the test tubes. After inoculation, test tubes were incubated. Soon after that, $1 \mathrm{ml}$ of Kovac's reagent was added to the test tubes and it was mixed thoroughly [10]. No cherry red color was observed. Hence, the bacterial isolates of the mobile phones found to be negative for indole test (Figure 3).

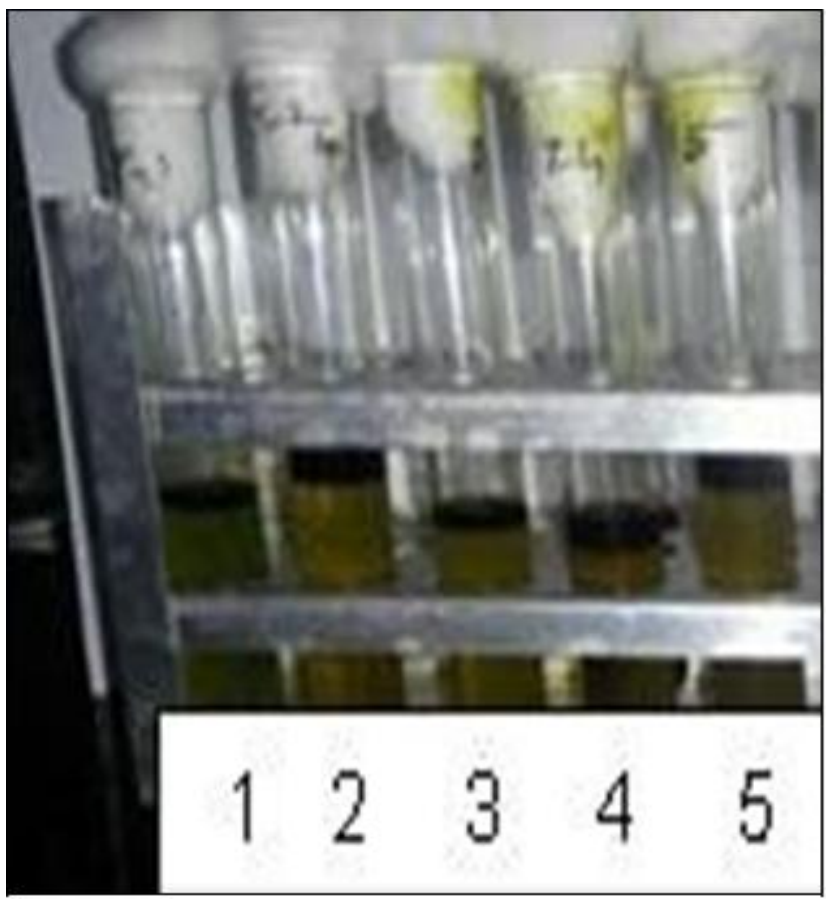

Fig. 3.Indole test for bacterial isolates. 1,2,3,4,5 are the indole results of bacterial isolates from 1-faculty, 2-student, 3- sweeper, 4-lab technician, 5- mechanic respectively.

\section{F. Methyl Red test}

MR-VP broth was prepared, transferred to the test tube and was autoclaved at $121^{\circ} \mathrm{C}$ for 15 minutes. Later, it was inoculated with bacterial isolates of the mobile phones. The test tubes were incubated and later methyl red solution was added in drop wise manner [11]. The development of Red color indicated bacterial isolates of the mobile phones were positive for methyl Red (Figure 4).

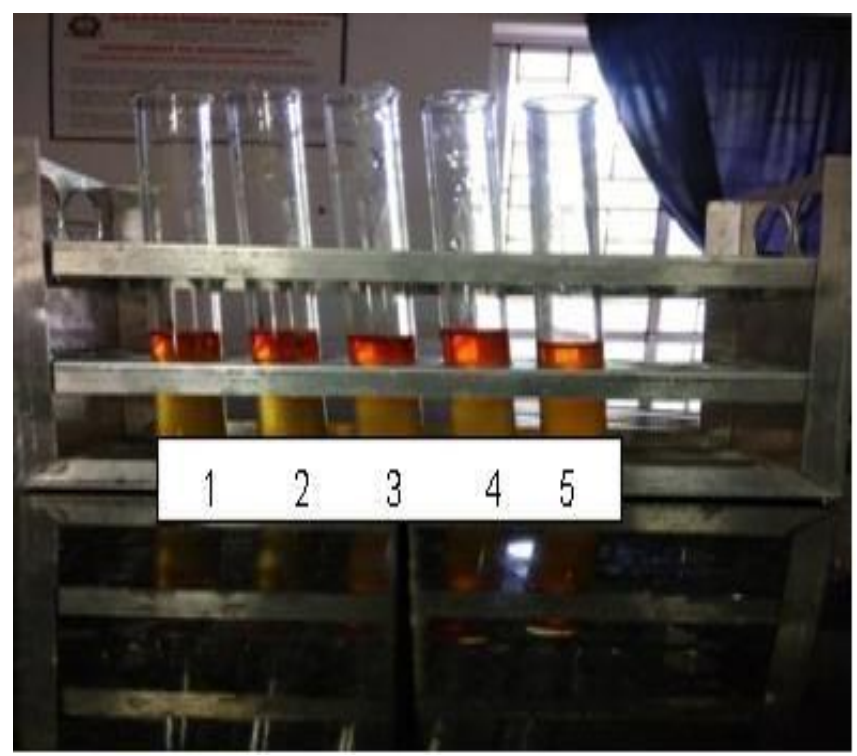

Fig. 4.Methyl Red test for bacterial isolates from 1-faculty, 2-student, 3- sweeper, 4-lab technician, 5-mechanic respectively.

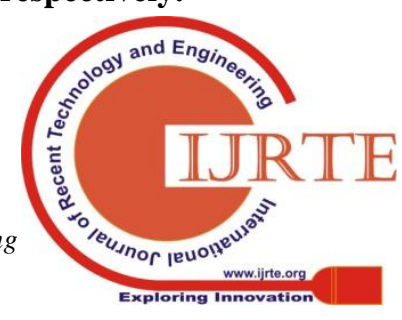




\section{G. Citrate utilization test}

The simmon's citrate agar was readied. It was sterilized in autoclave at $121^{\circ} \mathrm{C}$ at $15 \mathrm{lbs}$ for 15 minutes and was distributed into test tubes and agar slants were prepared. The bacterial isolates of the mobile phones were introduced by using inoculation loop. The tubes were incubated in incubator at $37^{\circ} \mathrm{C}$ for 24 hours [12]. After incubation, the results were observed. Blue color formation was observed. Hence, it was found to be positive for citrate utilization (Figure 5).

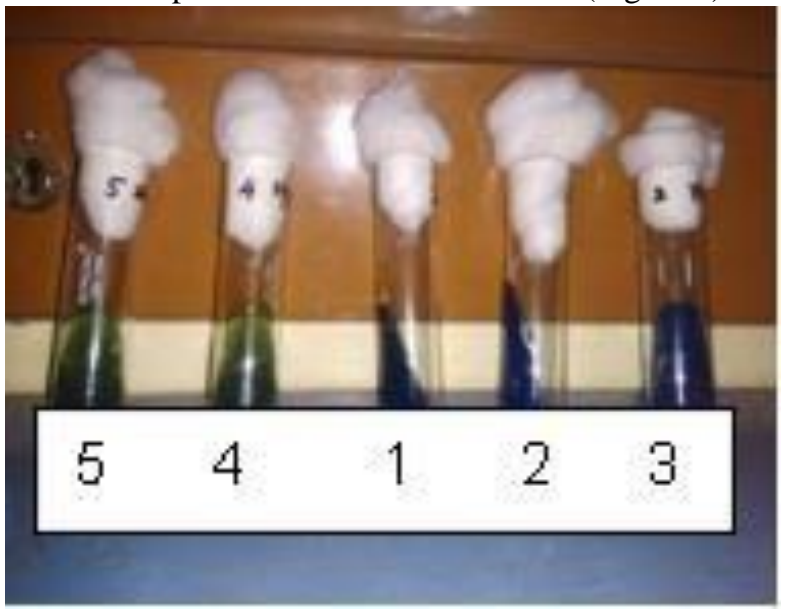

Fig. 5.Citrate utilization test for bacterial isolates from 1-faculty, 2- student, 3- sweeper, 4-lab technician, 5-mechanic respectively.

\section{H. Urease test}

Christensen's urea agar was prepared. It was sterilized in autoclave at $121^{\circ} \mathrm{C}$ at $15 \mathrm{lbs}$ for 15 minutes. The sterilized medium was distributed into test tubes and slants were prepared. The bacterial isolates of the mobile phones inoculated by using inoculation loop. The tubes were incubated in incubator at $37^{\circ} \mathrm{C}$ for 48 hours [13]. After incubation, the results were observed. Pink color formation was observed. Hence, it was found to be positive for Urease test (Figure 6).

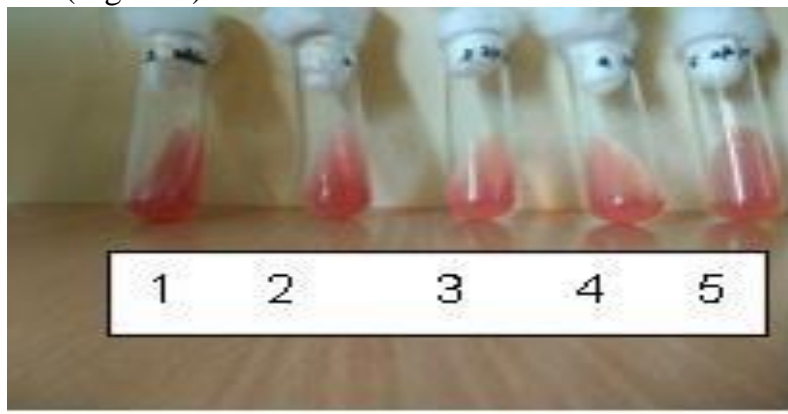

Fig. 6.Urease test for bacterial isolates from 1-faculty, 2-student, 3- sweeper, 4-lab technician, 5-mechanic respectively.

\section{TSI test}

TSI agar was prepared. It was sterilized in autoclave at $121^{\circ} \mathrm{C}$ at $15 \mathrm{lbs}$ for 15 minutes. The sterilized medium was distributed into test tubes and slants were prepared. The bacterial isolates of the mobile phones was inoculated by using inoculation loop. The tubes were incubated in incubator at $37^{\circ} \mathrm{C}$ for 48 hours [14]. After incubation, the results were observed. Red color formation was observed. Hence, it was found to be positive for TSI test (Figure 7)

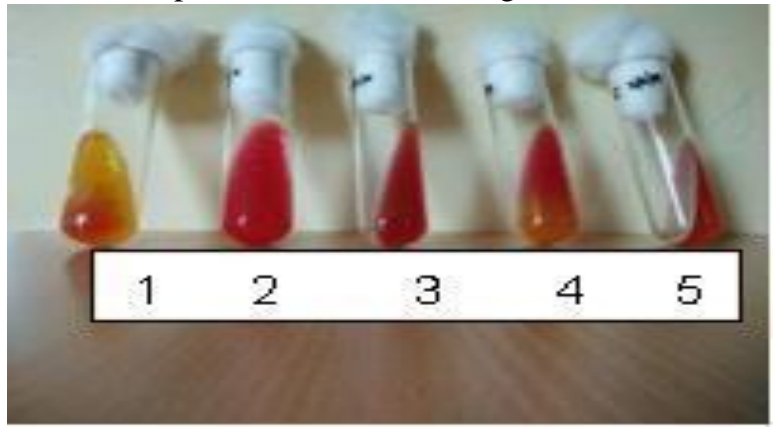

Fig. 7. TSI test for bacterial isolates from 1-faculty, 2-student, 3- sweeper, 4-lab technician, 5-mechanic respectively.

Our study confirms the results of earlier studies done on the mobile phone surface and reflects the potential threat by the microbiota on the surface of the mobile phones of the personnel such as operation theatre anesthetists [2], hospital personnel [ 3], [4], medical teaching faculty [5], hospitalized patients [6] and other group of peoples. Our study confirms the presence of bacterial microbiota on the mobile phones used extensively by teaching faculty, student, sweeper, lab technician and mechanic in an university.

\section{ACKNOWLEDGMENT}

The authors thank the management of Kalasalingam Academy of Research and Education for providing the laboratory facility for performing the experiments.

\section{REFERENCES.}

1. M.M.Hassan, and I.A. Ismail, "Isolation and molecular characterization of some pathogenic mobile phone bacteria" Biotechnology vol. 1. 2014, pp.

2. H.C. Jeske, W. Tiefenthaler, M. Hohlrieder, G. Hinterberger, and A Benzer "Bacterial contamination of anaesthetists' hands by personal mobile phone and fixed phone use in the operating theatre" Anaesthesia vol. 62 2007, pp. 904-906.

3. D. Daka, D. Yihdego, and E. Tadesse, "Level of contamination and antibiotic resistance of bacterial isolates from mobile phone of hcw's in hawassa referral hospital" AJMS vol. 7. 2015, pp.30.

4. P. Karkee, S.K. Madhup, P.Humagain, N. Thaku, and B. Timilsina, "Mobile phone: a possible vector of bacterial transmission in hospital setting” Kathmandu university medical journal vol.15. 2017,pp.217.

5. S. Apivanic, K. Malathum, W. Prapainich, T. Muntajit, S. Sirichot, and T.Pornmee, "Bacterial colonization of mobile phone carried by health-care providers: a cross-sectional study in a tertiary care teaching hospital" American journal of infection control vol.45. 2017, pp. 82

6. R.R. Brady, A.C. Hunt, A.Visvanathan, M.A. Rodrigues, C. Graham, C. Rae, P. Kalima, H.M. Paterson, and A.P. Gibb, "Mobile phone technology and hospitalized patients: a cross-sectional surveillance study of bacterial colonization, and patient opinions and behaviours" Clinical microbiology and infection vol. 17. 2011, pp.830-835.

7. R.B. Moyes, J. Reynolds, and D.P. Breakwell, "Preliminary staining of bacteria:negative stain" Current protocols in microbiology vol. 15. 2009, pp. A-3F.

8. D. Claus, "A standardized Gram staining procedure" World journal of microbiology and biotechnology vol. 8, 1992, pp. 451-452.

9. W.I. Taylor and D. Achanzar, "Catalase test as an aid to the identification of Enterobacteriacea" Appl. Environ. Microbiol vol.24, 1972, pp.5-61. 


\section{Bacterial Culture Dependent Effect on Mobile Phone's Surface}

10. J.M. Miller and J.W. Wright, "Spot indole test: evaluation of four reagents" Journal of clinical microbiology vol. 15, 1982, pp. 59-592.

11. A.L. Barry, K.L. Bernsohn, A.P. Adams, and L.D. Thrupp, "Improved 18-hour methyl red test" Appl. Environ. Microbiol vol. 20,1970, pp.866-70. 12. T.N.S Ragavachari, "The applicability of koser's citrate utilization test to sanitary water analysis in India" Indian journal of medical research vol.14, 1926, pp.47-51.

13. W.B. Christensen, "Urea decomposition as a means of differentiating Proteus and Paracolon cultures from each other and from Salmonella and Shigella types" Journal of bacteriology vol.52, 1946, pp. 461

14. J.K. Skilleren, and T.L. Overma, "Oxidase testing from kligler's iron agar and triple sugar iron agar slants" Current microbiology vol. 8, 1983, pp.269-271.

\section{AUTHORS PROFILE}

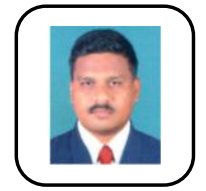

S. Sheik Asraf is an assistant professor working in Kalasalingam Academy of Research and Education. He had completed his Ph.D. thesis entitled "Computational and functional genomic analysis of beta-lacatamases, beta-galactosidase and cellulose synthase operon in Zymomonas mobilis" in Madurai Kamaraj University, Madurai in 2013. He has research experience in the broad areas of bioinformatics, genomics and microbiology. He is a recipient of Junior Research Fellowship from Department of Science and Technology, Government of India. He has received travel grants from the following agencies and institutes for participation in events held in India: UNESCO, IUBMB, RCBTE, ICGEB, National Science Foundation, Indo-US Science and Technology Forum and Department of Biotechnology. He has published 9 journal publications, 3 Book chapters, 25 conference abstracts. His current research focus is metagenomics and culture dependent study of inanimate objects.

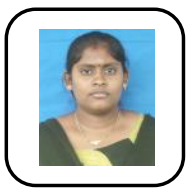

V.Priyanga had completed his B. Tech. Biotechnology from Kalasalingam Academy of Research and Education. Her B. Tech. Project is entitled "Screening of microbiota in mobile phone's surface through culture dependent and metagenomic approach".

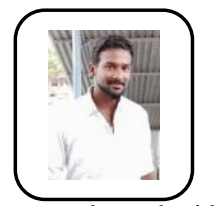

P.S.Bhuvaneshwaran had completed his B. Tech. Biotechnology from Kalasalingam Academy of Research and Education. His B. Tech. Project is entitled "Screening of microbiota in mobile phone's surface through culture dependent and metagenomic approach. His research focus is on bioadsorption of heavy metals in wastewater using exopolysaccharide extracted from marine algae.

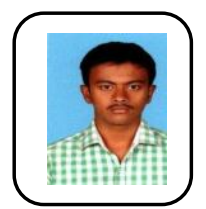

M. Devanand had completed his B. Tech Biotechnology from Kalasalingam Academy of Research and Education. His B. Tech. Project is entitled "Screening of microbiota in mobile phone's surface through culture dependent and metagenomic approach". 